\title{
Metal-free C-H mercaptalization of benzothiazoles and benzoxazoles using 1,3-propanedithiol as thiol source
}

\author{
Yan Xiao ${ }^{1}$, Bing Jing ${ }^{2}$, Xiaoxia Liu², Hongyu Xue ${ }^{2}$ and Yajun Liu ${ }^{* 2}$
}

\section{Letter}

\section{Address:}

${ }^{1}$ School of Pharmaceutical Engineering, Shenyang Pharmaceutical University, 103\# Wenhua Road, Shenyang, Liaoning 10016, China and ${ }^{2}$ School of Life Science and Medicine, Dalian University of Technology, 2\# Dagong Road, Panjin, Liaoning 124221, China

Email:

Yajun Liu* - yjliu85@dlut.edu.cn

* Corresponding author

Keywords:

benzothiazole; benzoxazole; $\mathrm{C}-\mathrm{H}$ functionalization; mercaptalization; 1,3-propanedithiol
Beilstein J. Org. Chem. 2019, 15, 279-284. doi:10.3762/bjoc. 15.24

Received: 25 September 2018

Accepted: 09 January 2019

Published: 29 January 2019

Associate Editor: J. Aubé

(C) 2019 Xiao et al.; licensee Beilstein-Institut. License and terms: see end of document.

\begin{abstract}
A facile and effective $\mathrm{C}-\mathrm{H}$ functionalization strategy for the synthesis of 2-mercaptobenzothiazoles and 2-mercaptobenzoxazoles is described. 1,3-Propanedithiol was employed to convert benzothiazoles and benzoxazoles to the corresponding heteroarylthiols in the presence of potassium hydroxide and DMSO. This novel protocol is featured by direct $\mathrm{C}-\mathrm{H}$ mercaptalization of heteroarenes and a simple reaction system.
\end{abstract}

\section{Introduction}

Both 2-mercaptobenzothiazoles and 2-mercaptobenzoxazoles are not only fundamental building blocks in organic synthesis, but also possess various biological activities (Figure 1) [1,2]. A complex of a transition metal (such as $\mathrm{Ru}, \mathrm{Pt}, \mathrm{Bi}$, etc.) with either a 2-mercaptobenzoxazole or a 2-mercaptobenzothiazole often provides cytotoxic activity against cancer cells [3-5] 2-Mercapto- $N$-(substituted arylidine)benzoxazole-5-carbohydrazide derivatives have promising anti-inflammatory activities [6]. 2-Mercapto-5-nitro-1,3-benzoxazole and its derivatives shows strong anthelmintic activity [7]. 2-Mercapto-5-chloro1,3-benzothiazoles possess antifungal activity against Candida albicans and Candida tropicalis [8] and 2-mercapto-1,3benzothiol and its derivatives exhibit inhibitory effects against thyroid peroxidase [9].
(Hetero)aryl thiols are often prepared from the corresponding halides through direct nucleophilic substitution [10-12] or metal-catalyzed $\mathrm{C}-\mathrm{S}$ coupling reactions [13]. Conventional methods for the synthesis of 2-mercaptobenzoxazoles and 2-mercaptobenzothiazoles include the interaction of 2-aminophenol or 2-haloanilines with carbon disulfide [14-16], or potassium ethyl xanthate $[17,18]$ (Scheme 1). In 2017, the Dong group reported a new method for the synthesis of 2-mercaptobenzoxazoles and 2-mercaptobenzothiazoles by cyclization of 2-aminothiophenols or 2-aminophenols with tetramethylthiuram disulfide in water [19]. Very recently, the Liu group developed a novel protocol for the synthesis of 2-mercaptobenzothiazoles via a three-component reaction of $o$-iodoanilines and $\mathrm{K}_{2} \mathrm{~S}$ in DMSO [20]. Another way to prepare 2-mercapto- 
<smiles>COc1ccc(/C=N/NC(=O)c2ccc3oc(S)nc3c2)cc1</smiles>
anti-inflammatory activity<smiles>Sc1nc2cc(Cl)ccc2s1</smiles><smiles>O=C(O)P(O)(O)(Cn1c(=O)sc2ccccc21)n1c(=S)sc2ccccc21</smiles>

anticancer activity

Figure 1: Representative examples of biologically active 2-mercaptobenzoxazoles and 2-mercaptobenzothiazoles.

benzothiazoles and 2-mercaptobenzoxazoles is the nucleophilic substitution of 2-halo-substituted benzothiazoles and benzoxazoles with sulfur-containing reagents including sodium thiosulfate [21], thiourea [22] and 1,2-ethanedithiol [23].

In the past decades, $\mathrm{C}-\mathrm{H}$ functionalization has become an effective strategy for constructing different molecules directly from simple arenes and alkanes. $\mathrm{C}-\mathrm{H}$ functionalization is an important method for $\mathrm{C}-\mathrm{S}$ coupling reactions [24,25]. For example, transition metal-catalyzed $\mathrm{C}-\mathrm{H}$ thiolation of benzothiazole or benzoxazole with a disulfide and a thiol provides easy access to the corresponding sulfides [26-34]. However, the examples using $\mathrm{C}-\mathrm{H}$ functionalization for preparing 2-mercaptobenzoxazoles or 2-mercaptobenzothiazoles are still rare. In 2009, the
Daugulis group reported that benzoxazole was converted to 2-mercaptobenzoxazoles in the presence of sulfur and potassium tert-butoxide, but only one example was shown [35]. In 2017, the Lei group reported a copper catalyzed C-H mercaptalization strategy using elementary sulfur as thiol source [36]. This conversion proceeds under very mild conditions, however, a metal catalyst and an additional ligand are required (Scheme 1).

Although some protocols have been developed, these methods still suffer from some drawbacks, such as limited substrate scope, low yield, and/or a complicated reaction system. Accordingly, developing a new and simple method for the synthesis of 2-mercaptobenzothiazoles and 2-mercaptobenzoxazoles is still desirable. As a continuous study on $\mathrm{C}-\mathrm{S}$ coupling reactions using aliphatic dithiols, herein we reported a simple and effective method for converting benzothiazoles and benzoxazoles to the corresponding thiols through direct $\mathrm{C}-\mathrm{H}$ mercaptalization using 1,3-propanedithiol as thiol source.

\section{Results and Discussion}

Previous studies in our group revealed that small aliphatic diols and dithiols are promising reagents for the synthesis of phenols and arylthiols, respectively [23,37]. Therefore, we envisioned that aliphatic dithiol may be able to work as thiol source in the $\mathrm{C}-\mathrm{H}$ mercaptalization of benzothiazole and benzoxazole as well, leading to the formation of 2-mercaptobenzothiazole and 2-mercaptobenzoxazole, respectively. We tested our hypothesis using benzothiazole (1a) as model substrate together with several aliphatic dithiols 2 . Initially, benzothiazole was treated with 3.0 equiv of each aliphatic dithiol and 5.0 equiv of $\mathrm{KOH}$ in

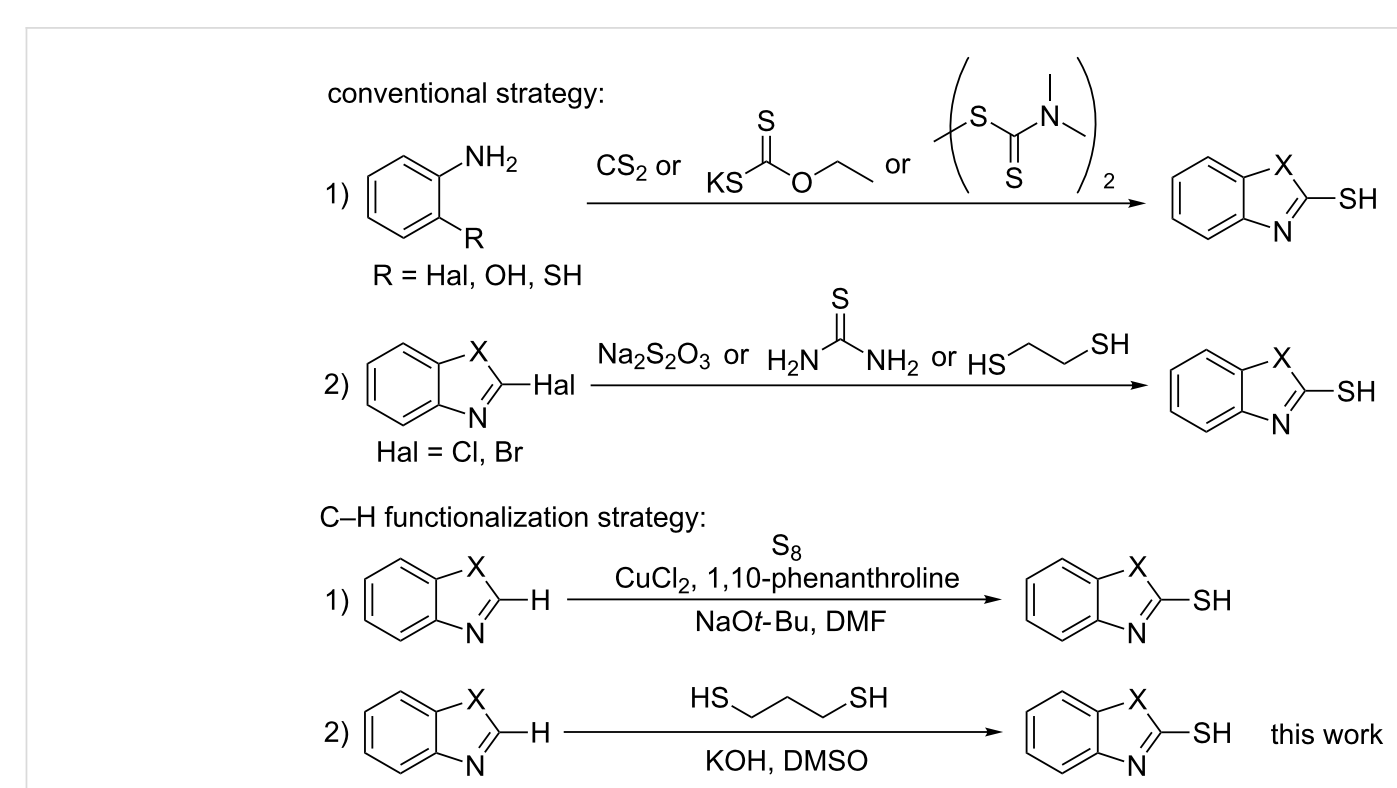


DMSO at $130{ }^{\circ} \mathrm{C}$. After $12 \mathrm{~h}$, we are delighted to find that $\mathbf{1 a}$ was predominantly converted to 2-mercaptobenzothiazole (3a). The investigation of the reaction mixture by proton nuclear magnetic resonance spectroscopy showed that no byproduct was formed. It should be noted that the length of aliphatic dithiols had a significant effect on the reaction performance. The reaction with 1,3-propanedithiol (2b) showed the best reaction performance, providing 3a with an isolated yield of $88 \%$ while the reaction with 1,2-ethanedithiol (2a) and 1,4butanedithol (2c) gave yields of $36 \%$ and $45 \%$, respectively (Table 1, entries 1-3). In the control reaction without aliphatic dithiol, 3a was not observed (Table 1, entry 4).

Table 1: Screening of the conditions for C-H mercaptalization of
benzothiazole. ${ }^{2}$

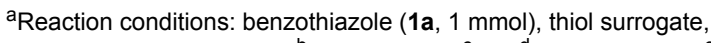
base, DMSO $(3 \mathrm{~mL}), 12 \mathrm{~h}$. ' Isolated yield. ${ }^{c} 6 \mathrm{~h}$. ${ }^{\mathrm{d}} 5 \mathrm{~mL}$ of DMSO. eDMF as solvent.

Shortening the reaction time to $6 \mathrm{~h}$ provided $79 \%$ yield of $\mathbf{3 a}$ (Table 1, entry 2). Lowering of the reaction temperature led to lower yields. No product was observed at $110^{\circ} \mathrm{C}$ while $20 \%$ yield of 3a was obtained at $120^{\circ} \mathrm{C}$ (Table 1 , entries 5 and 6). The investigation of different bases revealed that $\mathrm{KOH}$ was the most effective in this reaction in comparison to other bases such as $\mathrm{NaOt}$ - $\mathrm{Bu}, \mathrm{K}_{2} \mathrm{CO}_{3}$ and $\mathrm{Cs}_{2} \mathrm{CO}_{3}$ (Table 1, entries 7-9). Using 2.0 equiv of 1,3-propanedithiol did not lead to the loss of yield, however, only $46 \%$ yield was obtained when the amount of $1,3-$ propanedithiol was further lowered to 1.0 equiv. Five equivalents of $\mathrm{KOH}$ were required for this transformation as only $78 \%$ yield was obtained when 3.0 equiv of $\mathrm{KOH}$ was used (Table 1 , entries 10-12). DMSO was essential for this reaction because replacing DMSO with another organic solvent such as DMF significantly decreased the reaction yield to $8 \%$ (Table 1 , entry 13). Therefore, the optimized reaction conditions were obtained as follows: benzothiazole (1.0 mmol), 1,3-propanedithiol (2.0 equiv), $\mathrm{KOH}$ (5.0 equiv), DMSO $(3 \mathrm{~mL}), 130^{\circ} \mathrm{C}, 12 \mathrm{~h}$.

We further investigated several common thiol surrogates, which are often used in the $\mathrm{C}-\mathrm{H}$ mercaptalization of aryl halides. Under the optimized conditions, 1-butanethiol gave only $15 \%$ yield of 3a and many byproducts were formed (Table 1, entry 14). Other thiol surrogates including elementary sulfur, $\mathrm{Na}_{2} \mathrm{~S}_{2} \mathrm{O}_{3}, \mathrm{Na}_{2} \mathrm{~S} \cdot 9 \mathrm{H}_{2} \mathrm{O}$ and $\mathrm{K}_{2} \mathrm{~S}$ also provided very low yields (Table 1, entries 15-18). These results show that 1,3-propanedithiol is a promising thiol source for $\mathrm{C}-\mathrm{H}$ mercaptalization of benzothiazole.

With the optimized conditions in hand, we studied the substrate scope for this novel C-H mercaptalization strategy (Figure 2). Generally, benzothiazoles were converted to the corresponding heteroarylthiols in moderate to good yields. Functional groups including methyl and ethoxy groups as well as halogens are well tolerated under the developed reaction conditions. Benzoxazoles were also successfully converted to the corresponding thiols. The relatively lower yields can be attributed to the partial decomposition of benzoxazoles caused by $\mathrm{KOH}$ at high temperature.

In order to get more understanding of this novel $\mathrm{C}-\mathrm{H}$ mercaptalization strategy, several control experiments were carried out (Scheme 2). 2-Mercaptobenzothiazole was not observed when the reaction was carried out in the absence of either 1,3-propanedithiol or DMSO. This result indicate that 1,3-propanedithiol may react with DMSO and give an active intermediate, which can further convert benzothiazole to 2-mercaptobenzothiazole. Indeed, several articles have reported that thiols can be oxidized by DMSO to the corresponding disulfides [38,39].

Based on the above results and related references, a plausible reaction pathway is proposed (Scheme 3). Initially, 1,3-propanedithiol is possibly oxidized to disulfides 4 and 5 by DMSO. We failed to isolate and determinate these two sulfides, possibly because they are very active in the following coupling reactions. Both disulfides coupled with 1a to give the same $\mathrm{C}-\mathrm{S}$ coupling 


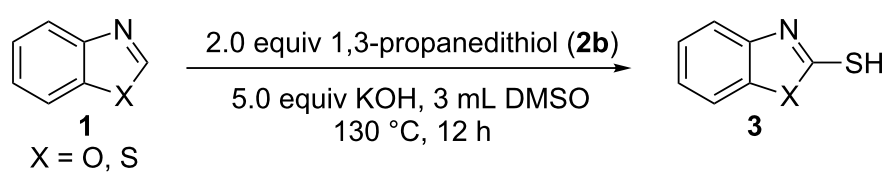



3a, $92 \%$<smiles>Sc1nc2c(Cl)cccc2s1</smiles>

$3 d, 67 \%$<smiles>Sc1nc2cc(Br)ccc2s1</smiles>

3 g, $81 \%$<smiles>Cc1ccc2oc(S)nc2c1</smiles>

3j, $75 \%$<smiles>Cc1cccc2sc(S)nc12</smiles>

$3 b, 83 \%$<smiles>Sc1nc2cc(Cl)ccc2s1</smiles>

$3 e, 74 \%$<smiles>Sc1nc2ccc(Br)cc2s1</smiles>

3h, $75 \%$<smiles>Sc1nc2cc(Cl)ccc2o1</smiles>

$3 \mathbf{k}, 69 \%$<smiles>CCOc1ccc2nc(S)sc2c1</smiles>

3c, $80 \%$

Figure 2: Substrate scope of the developed $\mathrm{C}-\mathrm{H}$ mercaptalization strategy. Reaction conditions: benzothiazole or benzoxazole 1 (1.0 mmol), 1,3-propanedithiol (2b, 2.0 equiv), $\mathrm{KOH}\left(5.0\right.$ equiv), DMSO $(3 \mathrm{~mL}), 130{ }^{\circ} \mathrm{C}, 12 \mathrm{~h}$.

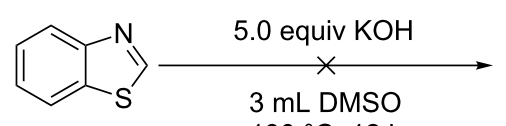

$130^{\circ} \mathrm{C}, 12 \mathrm{~h}$<smiles>Sc1nc2ccccc2s1</smiles>

$0 \%$


$130^{\circ} \mathrm{C}, 12 \mathrm{~h}$

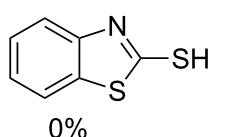

$0 \%$

product 6 [40]. As our previous work shows [23], (hetero)arylthioalkylthiols are easily converted to the corresponding (hetero)arylthiols in the presence of $\mathrm{KOH}$ and DMSO through an intramolecular nucleophilic substitution.

\section{Conclusion}

In this work, we developed a facile protocol for the direct synthesis of 2-mercaptobenzothiazoles and 2-mercaptobenzoxazoles from benzothiazoles and benzoxazoles. 1,3-Propanedithiol served as a thiol source and was superior to other common

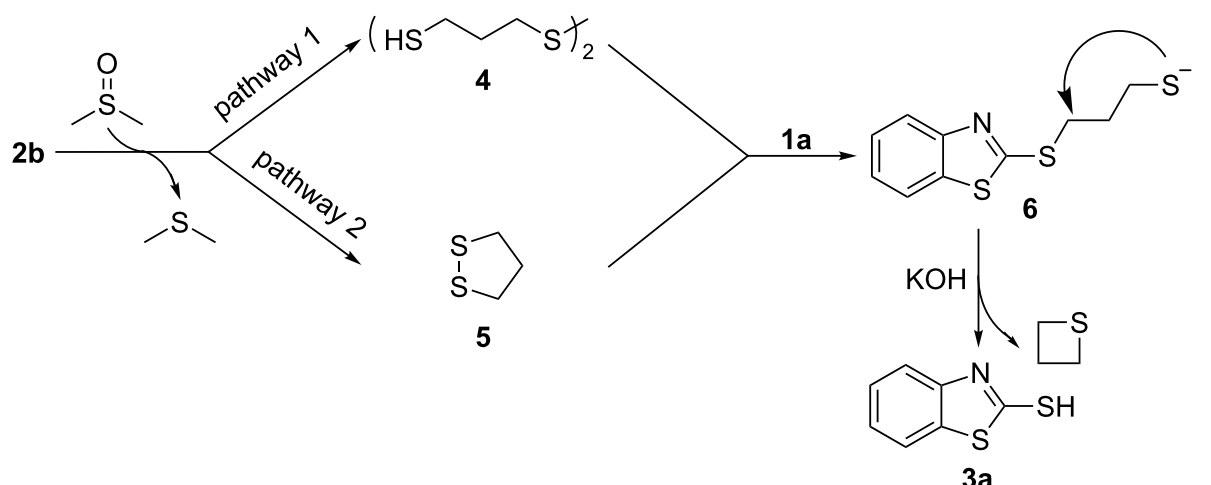


thiol surrogates under our developed conditions. DMSO was indispensable for this conversion and a preliminary mechanism study showed it served not only as a solvent but also as an oxidant. The developed reaction system required neither a metal catalyst nor a ligand. This simple method is expected to have potential application in both laboratory and industry.

\section{Supporting Information}

\section{Supporting Information File 1}

General experimental information, synthetic procedures, analytical data and NMR spectra for the reported compounds.

[https://www.beilstein-journals.org/bjoc/content/ supplementary/1860-5397-15-24-S1.pdf]

\section{Acknowledgements}

This work was supported by the Fundamental Research Funds for the Central Universities (Grant No. DUT17LK23; DUT17RC(4)31; DUT17LK41), the Natural Science Foundation of the Liaoning Province of China (Grant No. 20170540148), and the National Natural Science Foundation of China (Grant No. 31400307).

\section{ORCID ${ }^{\circledR}$ iDs}

Yajun Liu - https://orcid.org/0000-0002-9539-7279

\section{References}

1. Gill, R. K.; Rawal, R. K.; Bariwal, J. Arch. Pharm. (Weinheim, Ger.) 2015, 348, 155-178. doi:10.1002/ardp.201400340

2. Ranjit, S.; Lee, R.; Heryadi, D.; Shen, C.; Wu, J.; Zhang, P.; Huang, K.-W.; Liu, X. J. Org. Chem. 2011, 76, 8999-9007. doi:10.1021/jo2017444

3. Yarar, S.; Ozturk, I. I.; Banti, C. N.; Panagiotou, N.; Papatriantafyllopoulou, C.; Manoli, M.; Manos, M. J.; Tasiopoulos, A. J.; Hadjikakou, S. K. Inorg. Chim. Acta 2018, 471, 23-33. doi:10.1016/j.ica.2017.10.026

4. El-Asmy, H. A.; Butler, I. S.; Mouhri, Z. S.; Jean-Claude, B. J.; Emmam, M.; Mostafa, S. I. Inorg. Chim. Acta 2016, 441, 20-33. doi:10.1016/j.ica.2015.10.041

5. Mitra, R.; Samuelson, A. G. Eur. J. Inorg. Chem. 2014, 3536-3546. doi:10.1002/ejic.201402205

6. Prasad, A. V. G. S.; Rao, P. V.; Prasad, P. S. S. Int. J. Pharm. Res. Scholars 2014, 3, 63-68.

7. Satyendra, R. V.; Vishnumurthy, K. A.; Vagdevi, H. M.; Dhananjaya, B. L.; Shruthi, A. Med. Chem. Res. 2015, 24, 1342-1350. doi:10.1007/s00044-014-1207-6

8. Defrenza, I.; Catalano, A.; Carocci, A.; Carrieri, A.; Muraglia, M.; Rosato, A.; Corbo, F.; Franchini, C. J. Heterocycl. Chem. 2015, 52, 1705-1712. doi:10.1002/jhet.2222

9. Hornung, M. W.; Kosian, P. A.; Haselman, J. T.; Korte, J. J.; Challis, K.; Macherla, C.; Nevalainen, E.; Degitz, S. J. Toxicol. Sci. 2015, 146, 254-264. doi:10.1093/toxsci/kfv090
10. Testaferri, L.; Tingoli, M.; Tiecco, M. Tetrahedron Lett. 1980, 21 , 3099-3100. doi:10.1016/s0040-4039(00)77418-1

11. Testaferri, L.; Tiecco, M.; Tingoli, M.; Chianelli, D.; Montanucci, M. Synthesis 1983, 751-755. doi:10.1055/s-1983-30501

12. Shaw, J. E. J. Org. Chem. 1991, 56, 3728-3729. doi:10.1021/jo00011a057

13. Liu, Y.; Liu, S.; Xiao, Y. Beilstein J. Org. Chem. 2017, 13, 589-611. doi:10.3762/bjoc. 13.58

14. Wang, F.; Cai, S.; Wang, Z.; Xi, C. Org. Lett. 2011, 13, 3202-3205. doi:10.1021/ol2011105

15. Varun, B. V.; Prabhu, K. R. J. Org. Chem. 2014, 79, 9655-9668. doi:10.1021/jo501793q

16. Lou, C.; Zhu, N.; Fan, R.; Hong, H.; Han, L.; Zhang, J.; Suo, Q. Green Chem. 2017, 19, 1102-1108. doi:10.1039/c6gc03053j

17. Deligeorgiev, T. G.; Kaloyanova, S. S.; Lesev, N. Y.; Vaquero, J. J. Monatsh. Chem. 2011, 142, 895-899. doi:10.1007/s00706-011-0551-1

18. Liu, L.; Zhu, N.; Gao, M.; Zhao, X.; Han, L.; Hong, H. Phosphorus, Sulfur Silicon Relat. Elem. 2016, 191, 699-701. doi:10.1080/10426507.2015.1067208

19. Liu, X.; Liu, M.; Xu, W.; Zeng, M.-T.; Zhu, H.; Chang, C.-Z.; Dong, Z.-B. Green Chem. 2017, 19, 5591-5598. doi:10.1039/c7gc02311a

20. Zhu, X.; Li, W.; Luo, X.; Deng, G.; Liang, Y.; Liu, J. Green Chem. 2018, 20, 1970-1974. doi:10.1039/c8gc00477c

21. Foye, W. O.; Abood, N.; Kauffman, J. M.; Kim, Y.-H.; Patel, B. R. Phosphorus Sulfur Relat. Elem. 1980, 8, 205-207. doi:10.1080/03086648008078190

22. Watt, G. W. J. Org. Chem. 1939, 4, 436-441. doi:10.1021/jo01216a010 23. Liu, Y.; Kim, J.; Seo, H.; Park, S.; Chae, J. Adv. Synth. Catal. 2015, 357, 2205-2212. doi:10.1002/adsc.201400941

24. Shen, C.; Zhang, P.; Sun, Q.; Bai, S.; Hor, T. S. A.; Liu, X. Chem. Soc. Rev. 2015, 44, 291-314. doi:10.1039/c4cs00239c

25. Lee, C.-F.; Basha, R. S.; Badsara, S. S. Top. Curr. Chem. 2018, 376, 25. doi:10.1007/s41061-018-0203-6

26. Dai, C.; Xu, Z.; Huang, F.; Yu, Z.; Gao, Y.-F. J. Org. Chem. 2012, 77, 4414-4419. doi:10.1021/jo202624s

27. Rosario, A. R.; Casola, K. K.; Oliveira, C. E. S.; Zeni, G. Adv. Synth. Catal. 2013, 355, 2960-2966. doi:10.1002/adsc.201300497

28. Rafique, J.; Saba, S.; Frizon, T. E. A.; Braga, A. L. ChemistrySelect 2018, 3, 328-334. doi:10.1002/slct.201702623

29. He, Z.; Luo, F.; Li, Y.; Zhu, G. Tetrahedron Lett. 2013, 54, 5907-5910. doi:10.1016/j.tetlet.2013.08.097

30. Gandeepan, P.; Mo, J.; Ackermann, L. Chem. Commun. 2017, 53, 5906-5909. doi:10.1039/c7cc03107f

31. Liu, Y.; Wang, H.; Wang, C.; Wan, J.-P.; Wen, C. RSC Adv. 2013, 3, 21369-21372. doi:10.1039/c3ra42915f

32. Zhou, A.-X.; Liu, X.-Y.; Yang, K.; Zhao, S.-C.; Liang, Y.-M. Org. Biomol. Chem. 2011, 9, 5456-5462. doi:10.1039/c1ob05395g

33. Inomata, H.; Toh, A.; Mitsui, T.; Fukuzawa, S.-i. Tetrahedron Lett. 2013, 54, 4729-4731. doi:10.1016/j.tetlet.2013.06.104

34. Fukuzawa, S.-i.; Shimizu, E.; Atsuumi, Y.; Haga, M.; Ogata, K. Tetrahedron Lett. 2009, 50, 2374-2376. doi:10.1016/j.tetlet.2009.02.214

35. Popov, I.; Do, H.-Q.; Daugulis, O. J. Org. Chem. 2009, 74, 8309-8313. doi:10.1021/jo9015369

36. Yan, H.; Huang, Z.; Chen, M.; Li, C.; Chen, Y.; Gao, M.; Lei, A. Org. Biomol. Chem. 2017, 15, 8276-8279. doi:10.1039/c7ob02036h

37. Liu, Y.; Park, S. K.; Xiao, Y.; Chae, J. Org. Biomol. Chem. 2014, 12, 4747-4753. doi:10.1039/c4ob00649f 
38. Le Quéméner, F.; Subervie, D.; Morlet-Savary, F.; Lalevée, J.;

Lansalot, M.; Bourgeat-Lami, E.; Lacôte, E. Angew. Chem., Int. Ed.

2018, 57, 957-961. doi:10.1002/anie.201710488

39. Liu, X. G.; Wu, J. P.; Liang, X. M.; Wang, D. Q. Chin. J. Org. Chem. 2001, 21, 549-556.

40. Zou, L.-H.; Reball, J.; Mottweiler, J.; Bolm, C. Chem. Commun. 2012, 48, 11307-11309. doi:10.1039/c2cc36711d

\section{License and Terms}

This is an Open Access article under the terms of the Creative Commons Attribution License

(http://creativecommons.org/licenses/by/4.0). Please note that the reuse, redistribution and reproduction in particular requires that the authors and source are credited.

The license is subject to the Beilstein Journal of Organic Chemistry terms and conditions:

(https://www.beilstein-journals.org/bjoc)

The definitive version of this article is the electronic one which can be found at: doi:10.3762/bjoc. 15.24 